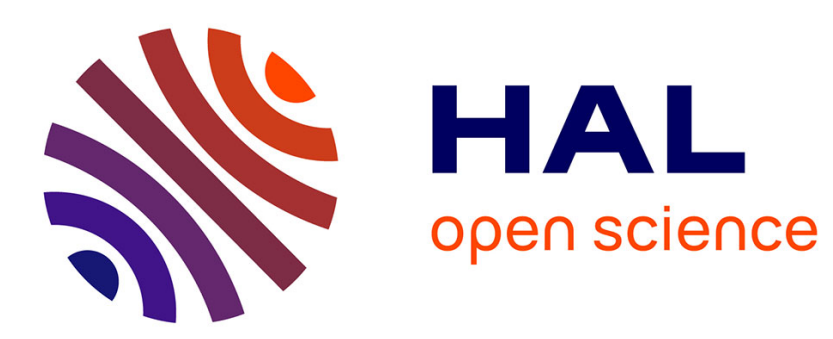

\title{
An assessment of the impact of copper mine tailings disposal on meiofaunal assemblages using microcosm bioassays
}

\author{
Matthew R. Lee, Juan A. Correa
}

\section{To cite this version:}

Matthew R. Lee, Juan A. Correa. An assessment of the impact of copper mine tailings disposal on meiofaunal assemblages using microcosm bioassays. Marine Environmental Research, 2007, 64 (1), pp.1. 10.1016/j.marenvres.2006.11.001 . hal-00562963

\section{HAL Id: hal-00562963 https://hal.science/hal-00562963}

Submitted on 4 Feb 2011

HAL is a multi-disciplinary open access archive for the deposit and dissemination of scientific research documents, whether they are published or not. The documents may come from teaching and research institutions in France or abroad, or from public or private research centers.
L'archive ouverte pluridisciplinaire HAL, est destinée au dépôt et à la diffusion de documents scientifiques de niveau recherche, publiés ou non, émanant des établissements d'enseignement et de recherche français ou étrangers, des laboratoires publics ou privés. 


\section{Accepted Manuscript}

An assessment of the impact of copper mine tailings disposal on meiofaunal assemblages using microcosm bioassays

Matthew R. Lee, Juan A. Correa

PII:

S0141-1136(06)00206-6

DOI:

10.1016/j.marenvres.2006.11.001

Reference:

MERE 3077

To appear in:

Marine Environmental Research

Received Date: $\quad 31$ October 2005

Revised Date: $\quad 7$ March 2006

Accepted Date: $\quad 2$ November 2006

Please cite this article as: Lee, M.R., Correa, J.A., An assessment of the impact of copper mine tailings disposal on meiofaunal assemblages using microcosm bioassays, Marine Environmental Research (2006), doi: 10.1016/ j.marenvres.2006.11.001

This is a PDF file of an unedited manuscript that has been accepted for publication. As a service to our customers we are providing this early version of the manuscript. The manuscript will undergo copyediting, typesetting, and review of the resulting proof before it is published in its final form. Please note that during the production process errors may be discovered which could affect the content, and all legal disclaimers that apply to the journal pertain. 


\title{
An assessment of the impact of copper mine tailings disposal on meiofaunal assemblages using microcosm bioassays.
}

\author{
Matthew R. Lee ${ }^{*, 1,2}$ and Juan A. Correa ${ }^{1}$ \\ Departamento de Ecología, Center for Advanced Studies in Ecology and \\ Biodiversity ${ }^{1}$ and Estación Costera de Investigaciones Marinas ${ }^{2}$, Facultad de \\ Ciencias Biológicas, Pontificia Universidad Católica de Chile, Alameda 340, \\ Santiago, Chile
}

\begin{abstract}
Microcosms were used to assess the impact of copper mine tailings disposal on the littoral meiofaunal assemblages of the Atacama region of northern Chile. The specific purpose was to establish a cause and effect relationship between the elevated copper concentrations and altered meiofaunal assemblages observed at the study sites. Meiofaunal assemblages were exposed to a series of copper concentrations to assess general toxicity, both densities and taxa diversities decreased with increasing copper. Natural coarse sediments were mixed with a tailings substitute to assess the physical impact of the tailings dumping on meiofaunal assemblages. Meiofaunal assemblage densities increased with increasing amounts of tailings substitute, entirely due to an increase in surface utilising foraminiferans. However, taxa diversities decreased as the interstitial spaces became blocked. Finally, the microcosms were used to conduct bioassays of sediments and seawaters from the impacted sites. The sediments from the impacted sites proved to be toxic resulting in reduced meiofau-
\end{abstract}


nal densities and taxa diversities. Seawater samples did not prove to be significantly toxic. The use of microcosms has allowed the effects of the physical and chemical components of tailings to be assessed individually, which was not possible in the field. Additionally, it allowed a cause and effect relationship to be established between elevated concentrations of porewater copper observed in the field and the reduced densities and taxa diversities of the meiofaunal assemblages observed at the same sites.

Key words: Meiofauna, Microcosms, Metals, Copper, Bioassay, Chile

\section{Introduction}

Copper mine tailings were dumped into the coastal environment near Chañaral in northern Chile for most of the last century, resulting in the formation of large tailings deposits in the sub-littoral (Castilla \& Nealler, 1978) and littoral zones of this area (Castilla, 1983). Initially the tailings were deposited in Chañaral bay (Fig. 1) and as a result the new shore line is a kilometre further out to sea (Castilla, 1983). In the 1970's the tailings were diverted to a new dumping point at Caleta Palito, ten kilometres to the north of Chañaral bay (Fig. 1). A second large tailings beach formed to the north of Caleta Palito in the littoral zone between Caleta La Lancha and Caleta Agua Hedionda (Fig. 1). The beaches around Caleta Palito were not smothered but there was a significant amount of tailings mixed in with the natural sediment. The dumping of solid tailings waste ceased in 1992, and since then only 'clear water' tailings have entered coastal waters. The impact of this tailings deposition on the coastal ecosystems has been extensively studied, with a primary focus on the

*mlee@bio.puc.cl 


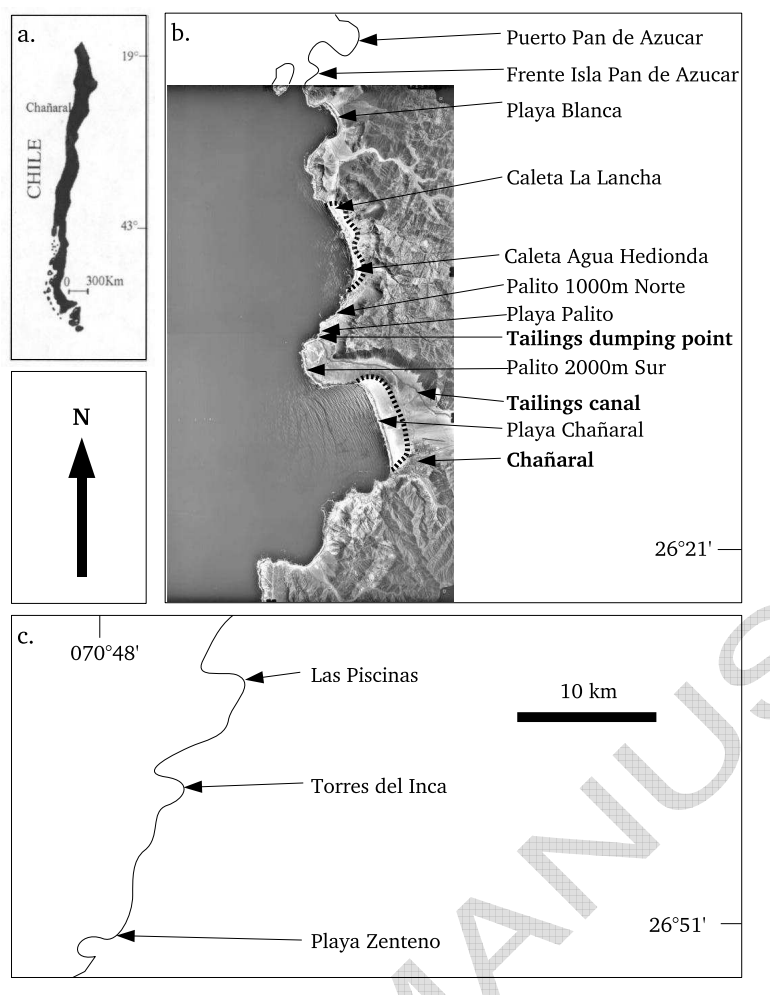

Fig. 1. A map of Chile indicating Chañaral (a) and showing the locations of the sampling sites (b) the northern and central sites, (c) the reference sites. The dashed line in (b) indicates the approximate position of the original coastline.

effects on the rocky-shore environment. Studies concerning the sedimentary environment include Castilla \& Nealler (1978); Castilla (1983); Lee, Correa \& Castilla (2001b); Lee, Correa \& Zhang (2002); Lee \& Correa (2004, 2005).

Meiofauna were selected to study the impact of copper mine tailings disposal on the high-energy sandy beaches of northern Chile because of their higher diversity when compared with macrofauna in this environment. The macro- 
faunal diversity of Chilean high-energy sandy beaches is low, typically between one and ten species (Jaramillo, McLachlan \& Coetzee, 1993; Jaramillo, 1994) depending on the physical nature of the beach. In addition to their higher diversity the meiofauna also have a number of other advantages over macrofauna for this type of study (Coull \& Chandler, 1992). The macrofaunal species encountered in the beaches of this area have a pelagic dispersal phase in their life-cycles. As a result larvae, usually the most sensitive stage, are not exposed to the contaminants present in the sediment. This, combined with recruitment derived from populations outside the affected area, can serve to mask the impact that contaminants may have on the littoral environment. The diversity of meiofauna provides a wide range of physiological responses and, therefore, a larger source of potential end points and a more precise understanding of the true impact of the contaminant(s).

Microcosms are scale models of natural systems which share sufficient features with them to provide a reliable insight into the processes and possible responses of the natural system to change (Lawler, 1998). The use of microcosms in pollution studies has been tried in a number of environments, including wetlands (Johnson, 1986), salt-marshes (O’Neill, Cripe, Mueller, Connolly \& Prichard, 1989), soils (Van Beelen, Fleuren-Kemila, Huys, van Montfort \& van Vlaardingen, 1991), freshwaters (Meador, Taub, \& Sibley, 1992), estuaries (Lauth, Scott, Cherry \& Buikema, 1996), and the deep-sea (Gross, 2000). Chapman \& Long (1983) pointed out the need for relevant bioassays as part of a broad-based approach in determining the impact of pollutants in the marine sedimentary environment. In this case we chose to use a multi-species microcosm methodology as a bioassay. The most recent microcosm bioassay studies using meiofauna include those of Austin \& Somerfield (1997); Chan- 
dler, Coull, Schizas \& Donelan (1997); Carman, Fleeger, \& Pomarico (2000);

Millward, Carman, Fleeger, Gambrell, Powell, \& Rouse (2001); Schratzberger, Wall, Reynolds, Reed, \& Waldock (2002) and Suderman \& Thistle (2003). All the groups used microcosms with meiofaunal assemblages as bioassays of contaminated sediments. Austin \& Somerfield (1997); Millward et al. (2001) and Schratzberger et al. (2002) studied the effects of metals on estuarine or saltmarsh meiofauna assemblages. Carman et al. (2000) and Suderman \& Thistle (2003) studied the effects of hydrocarbon pollution on meiofaunal assemblages. Finally, Chandler et al. (1997) studied the effects of the pesticide chlorpyrifos on harpacticoid copepod assemblages.

The objective of the work presented here was twofold. First, to assess the effect of two components of the copper mine tailings: (i) the toxicity of elevated metal concentrations and (ii) the physical impact of the reducing the interstitial space. Second, to use the microcosms approach to bioassay sediments and seawaters from field sites in an attempt to establish a cause-effect relationship between the observed elevated porewater copper concentrations (Lee et al., 2002) and the reduced meiofaunal assemblage density and taxa diversity (Lee \& Correa, 2005).

\section{Materials and Methods \\ 2.1 Microcosm methodology}

The standard microcosm protocol used for these experiments was defined after a series of preliminary experiments designed to establish: (i) the best method of aerating the sediment, from above (in the water column) or below (through 
the sediment), (ii) the changes in the meiofaunal assemblages over the experimental period compared to changes in the field assemblages, 'the microcosm effect', (iii) the best location for the microcosms, indoors or outdoors, and (iv) whether or not to exclude macrofauna (Emerita analoga)from the microcosms. The details of these experiments are outlined in Lee (2001a). Briefly, it was decided to aerate the microcosms from above, to maintain the microcosms indoors and remove E. analoga.

Each microcosm unit (Fig. 2) consisted of a $100 \mathrm{~mm}$ length of PVC plumbing tubing, $110 \mathrm{~mm}$ in diameter, to one end of which a PVC cap was attached and sealed with transparent silicone, both inside and out. All microcosms units were acid washed in $10 \% \mathrm{HNO}_{3}$ for 48 hours prior to the start of each experiment. During the experimental run each microcosm was fitted with a thin clear plastic lid, held in place by an elastic band to prevent evaporation of the seawater and a consequent increase in salinity. Air was delivered to each microcosm through a flexible plastic tube, which pierced the lid. Before entering the microcosm, air was passed through a freshwater filter to remove any potential residues derived from the air pump. Within the microcosm, air pressure was equalised with the pressure outside by means of an air lock, which consisted of a piece of tube with a raw cotton wool plug. All microcosms were placed in a water bath with running sea water for the duration of the experiment. The experimental room had no windows and an ambient temperature of $15^{\circ} \mathrm{C} \pm 2^{\circ} \mathrm{C}$. All the experiments were run in continuous low intensity light (Philips 40W fluorescent tubes), as light was assumed not to penetrate more than a few millimetres into the sediment (Kuhl, Lassen \& Jorgensen, 1994).

The 'seed' meiofaunal assemblages were obtained from the reference sites; Las Salinas for coarse sands and Playa Grande for fine sands (Table 1), both 


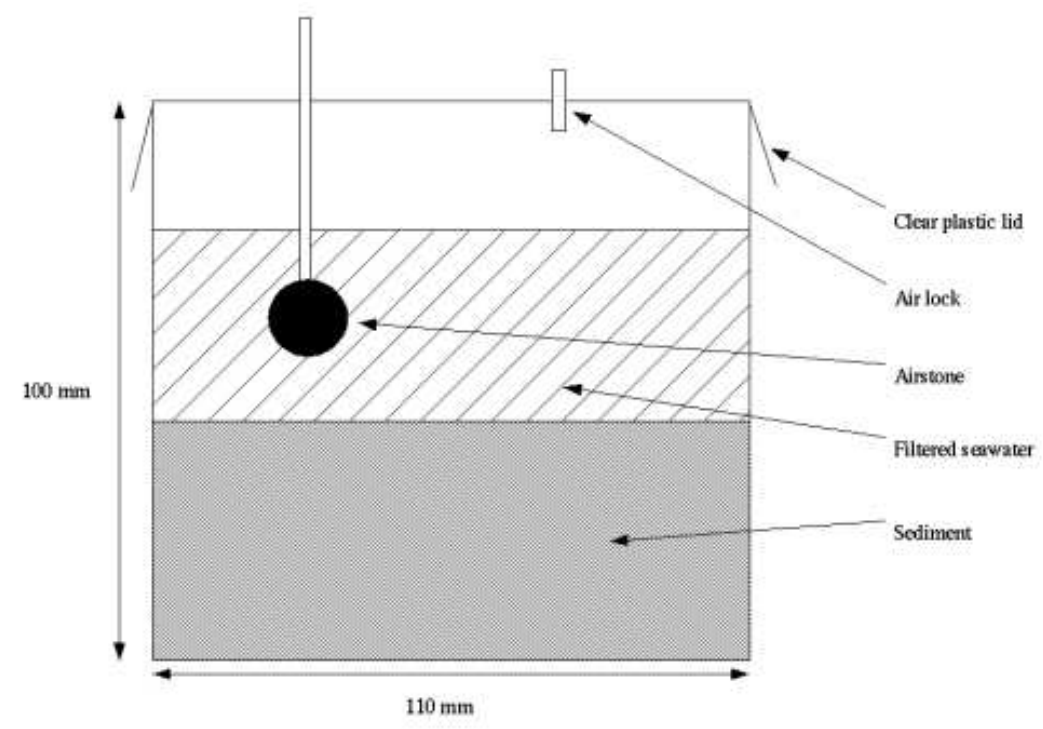

Fig. 2. Microcosm unit

located in Las Cruces, Region V, central Chile. Fresh sediment for the 'seed' assemblages was collected from the reference sites immediately before the start of each experiment. As meiofauna are known to have a heterogeneous distribution (e.g. Findlay, 1981; Coull, 1988), small amounts of sand were collected from various points on the beach, but all at the same tidal level. The collected sediment was thoroughly mixed to distribute the meiofauna homogeneously through the sediment. The macrofauna, predominantly the mole crab E. analoga, were removed. Subsequently, $100 \mathrm{~cm}^{3}$ of this sediment was added to each microcosm to act as a 'seed' population. Base sediments were those which were manipulated to form treatments. Sediments were collected from the field, frozen and then thawed twice in order to defaunate the sediment (Austin, McEvoy \& Warwick, 1994). The sediment was then dried in an oven at $60^{\circ} \mathrm{C}$ for 24 hours. Dead macrofauna (e.g. E. analoga) were picked out by hand and then the sediment was stored in Ziploc ${ }^{\mathrm{TM}}$ bags in the dark until required. 
Table 1

The detailed location of the beaches used in this study. The column Md refers to the graphic mean sediment grain size in units of phi $(\phi)$. The $\mathrm{Cu}_{\mathrm{pw}}$ column gives the labile copper concentrations in the porewater of each site in $\mu \mathrm{g} \mathrm{Cu} \mathrm{L}^{-1}$.

\begin{tabular}{|c|c|c|c|c|c|}
\hline Beach & Code & $\operatorname{Md}(\phi)$ & $\mathrm{Cu}_{\mathrm{pw}}$ & Lat. & Long. \\
\hline Puerto Pan de Azucar & Pue & -0.03 & 14.5 & $26^{\circ} 08.3^{\prime} S$ & $070^{\circ} 39.3^{\prime} W$ \\
\hline Playa Blanca & Bla & 2.43 & 59.0 & $26^{\circ} 11.1^{\prime} S$ & $070^{\circ} 39.2^{\prime} W$ \\
\hline Caleta La Lancha & Lan & 1.96 & 366.2 & $26^{\circ} 13.4^{\prime} S$ & $070^{\circ} 39.2^{\prime} \mathrm{W}$ \\
\hline Palito $100 \mathrm{~m}$ Norte & Mil & -0.78 & 101.1 & $26^{\circ} 16.1$ & $070^{\circ} 39.2^{\prime} W$ \\
\hline Playa Palito & Pal & -0.78 & 290.9 & $26^{\circ} 16.3^{\prime} S$ & $070^{\circ} 39.3^{\prime} W$ \\
\hline Playa Chañaral & Cha & 2.30 & 129.4 & $26^{\circ} 20.5^{\prime} S$ & $070^{\circ} 37.4^{\prime} W$ \\
\hline Las Salinas & Sal & 0.38 & $0.2^{*}$ & $33^{\circ} 29.5^{\prime} S$ & $071^{\circ} 38.1^{\prime} W$ \\
\hline Playa Grande & & 1.66 & $0.2^{*}$ & $33^{\circ} 30.3^{\prime} S$ & $071^{\circ} 36.6^{\prime} W$ \\
\hline
\end{tabular}

* The $\mathrm{Cu}_{\mathrm{pw}}$ for Sal and Pgr are the value for seawater at the marine station, Sal and Pgr lie to the immediate north and south of the station respectively.

\subsection{Copper toxicity microcosms}

Copper spiked sediments were prepared as follows. Base sediments from Las Salinas (coarse) were prepared as described above and spiked with: 50, 100, and $150 \mu \mathrm{g} \mathrm{Cu} \mathrm{L}^{-1}$ using $\mathrm{CuSO}_{4}$ as standard stock solutions. The fourth treatment was a control of $10 \mu \mathrm{m}$ filtered seawater from Las Cruces $\left(0.17 \mu \mathrm{g} \mathrm{Cu} \mathrm{L}^{-1}\right.$ (s.e. \pm 0.01$)$ ). The stock $\mathrm{CuSO}_{4}$ solution was made up using a Merck ${ }^{\mathrm{TM}}$ copper standard $\left(1 \mathrm{~g} \mathrm{~L}^{-1}\right)$, which was diluted to make up the test treatments. Sufficient base 
sediment was placed into four acid washed plastic buckets $\left(10 \% \mathrm{HNO}_{3}\right.$ for 48 hours), one for each treatment, and the test solutions added to each. The buckets were covered and left for 48 hours to allow the copper to form an equilibrium with the various ligands present in the sediment/seawater matrix. Five replicate microcosms were prepared for each treatment using $400 \mathrm{ml}$ of treatment sediment and $100 \mathrm{ml}$ of 'seed' sediment from Las Salinas. The sediments were gently mixed together by hand and the trials run for six weeks.

\subsection{Tailings substitute microcosms}

The tailings substitute test sediments were prepared as follows. The base sediments were obtained from Las Salinas (coarse) and prepared as described above. The tailings substitute was obtained from Playa Grande (fine) and prepared in the same manner as the base sediments. The two sediments were mixed together to form the following treatments: 100\% Las Salinas (Control), 75\% Las Salinas + 25\% Playa Grande, 50\% Las Salinas + 50\% Playa Grande, and $25 \%$ Las Salinas $+75 \%$ Playa Grande. Treatments will be referred to from this point on by the amount of tailings substitute (Playa Grande); i.e. Control (0\%), 25\%, 50\% and 75\%. Five replicate microcosms were prepared for each treatment using $400 \mathrm{ml}$ of treatment sediment and $100 \mathrm{ml}$ of 'seed' sediment from Las Salinas. The sediments were gently mixed together by hand and the trials run for six weeks. 


\subsection{Sediment and seawater bioassays}

Sediment bioassays were conducted using five replicate sediment samples collected from the study sites in the Chañaral area (Fig. 1). Five, approximately $1 \mathrm{~L}$ sediment samples were placed in $\mathrm{Ziploc}^{\mathrm{TM}}$ bags at each site, packed into a cooler and immediately returned to the laboratory. The sediments were then subjected to the freeze-thaw method (Austin et al., 1994) to remove the meiofauna. The sediments were divided into two groups, coarse and fine. Coarse sediments were collected from Puerto Pan de Azucar, Palito 1000m Norte, and Playa Palito (Fig. 1, Table 1) and the reference sediment and 'seed' assemblage for the coarse bioassays from Las Salinas (Table 1). Fine sediments were collected from Playa Blanca, Caleta La Lancha, and Playa Chañaral (Fig. 1, Table 1) and the reference sediment and 'seed' assemblages for the fine bioassays from Playa Grande (Table 1). The seawater used in these microcosms was $10 \mu \mathrm{m}$ filtered seawater from Las Cruces $\left(0.17 \mu \mathrm{g} \mathrm{Cu} \mathrm{L}{ }^{-1}\right.$ (s.e. \pm 0.01$)$ ). Five replicate microcosms were set-up for each site and run for six weeks.

Seawater bioassays were conducted using five replicate seawater samples collected from the surf zone of the sites around Chañaral. The samples were divided into two groups, coarse and fine sediment sites, collected from the same sites used for the sediment bioassays. Samples were filtered on site $(45 \mu \mathrm{m})$ and placed into acid-washed $\left(10 \% \mathrm{HNO}_{3}\right.$ for 48 hours) 1 L plastic bottles, then into a cooler and returned immediately to the laboratory. The reference waters and 'seed' assemblages were from the same two sites as before. The base sediments in the seawater bioassays came from Las Salinas (coarse) and Playa Grande (fine). Five replicate microcosms were set-up for each site and run for six weeks. 


\subsection{Sample processing and analysis}

At the end of each experimental run the sediment in each microcosm was mixed and a single $50 \mathrm{~cm}^{3}$ sample taken, giving five replicate samples for each treatment. The samples were fixed for at least four days in $10 \%$ formalin. The meiofauna were extracted from the sediment using a simple decantation technique (Pfannkuche \& Thiel, 1988). Samples were shaken for approximately 30 seconds and the supernatant poured through a $45 \mu \mathrm{m}$ mesh. This process was repeated five times for each sample and had an extraction efficiency of 95\% (Lee, 2001a). The meiofauna were enumerated in a grided Petri dish under a binocular microscope (Wild M5). Diversity (number of groups $\approx S$ ) was evaluated at a high taxonomic level and here will be referred to as 'taxa diversity' see Warwick (1988) for justification.

\subsection{Metal analyses}

Labile metal concentrations in both the seawater and the sediment porewater from the study sites were determined using the diffusive gradients in thinfilms (DGT) technique (Davidson \& Zhang, 1994; Zhang \& Davidson, 1995;

Zhang, Zhao, Sun, Davidson \& McGrath, 2001). As only copper concentrations showed a strong association with the distribution of the tailings (Lee et al., 2002), the information presented in this report is restricted to this metal. For a detailed discussion of the distribution of metals in this area see Lee et al. (2002). 


\subsection{Statistical analyses}

The meiofauna data were analysed using standard univariate analyses (SYSTAT v9.0, Spss Inc.) and multivariate analyses (PRIMER, Plymsolve). The following multivariate analyses were conducted on 4th root transformed data: analysis of similarities (ANOSIM) (Clarke \& Green, 1988; Clarke, 1993), nonmetric multidimensional scaling (MDS) (Field, Clarke \& Warwick, 1982; Clarke, 1993), and similarities percentage analysis (SIMPER) (Clarke, 1993).

\section{Results}

\subsection{Copper toxicity microcosms}

A significant decline (Fig. 3) in meiofaunal assemblage density was observed with increasing copper concentration (Kruskal-Wallis $(\mathrm{H})$ test: $\mathrm{H}=15.764$, $\mathrm{p}=0.001)$, which was also the case for taxa diversity $(\mathrm{H}=10.395, \mathrm{p}=$ 0.015). Foraminiferans $(\mathrm{H}=13.038, \mathrm{p}=0.005)$, harpacticoid copepods $(\mathrm{H}$ $=10.382, \mathrm{p}=0.016)$ and polychaetes $(\mathrm{H}=11.163, \mathrm{p}=0.011)$ all showed $\mathrm{a}$ significant decline in density with increasing copper concentration. Nematodes and ostracods showed a decline in density with increasing copper concentration but this was not significant. Turbellarians, on the other hand, did not show any significant variation in density over the range of treatments. Both halacarids and tardigrades were present in the microcosms but did not show any variation in density over the range of treatments. 


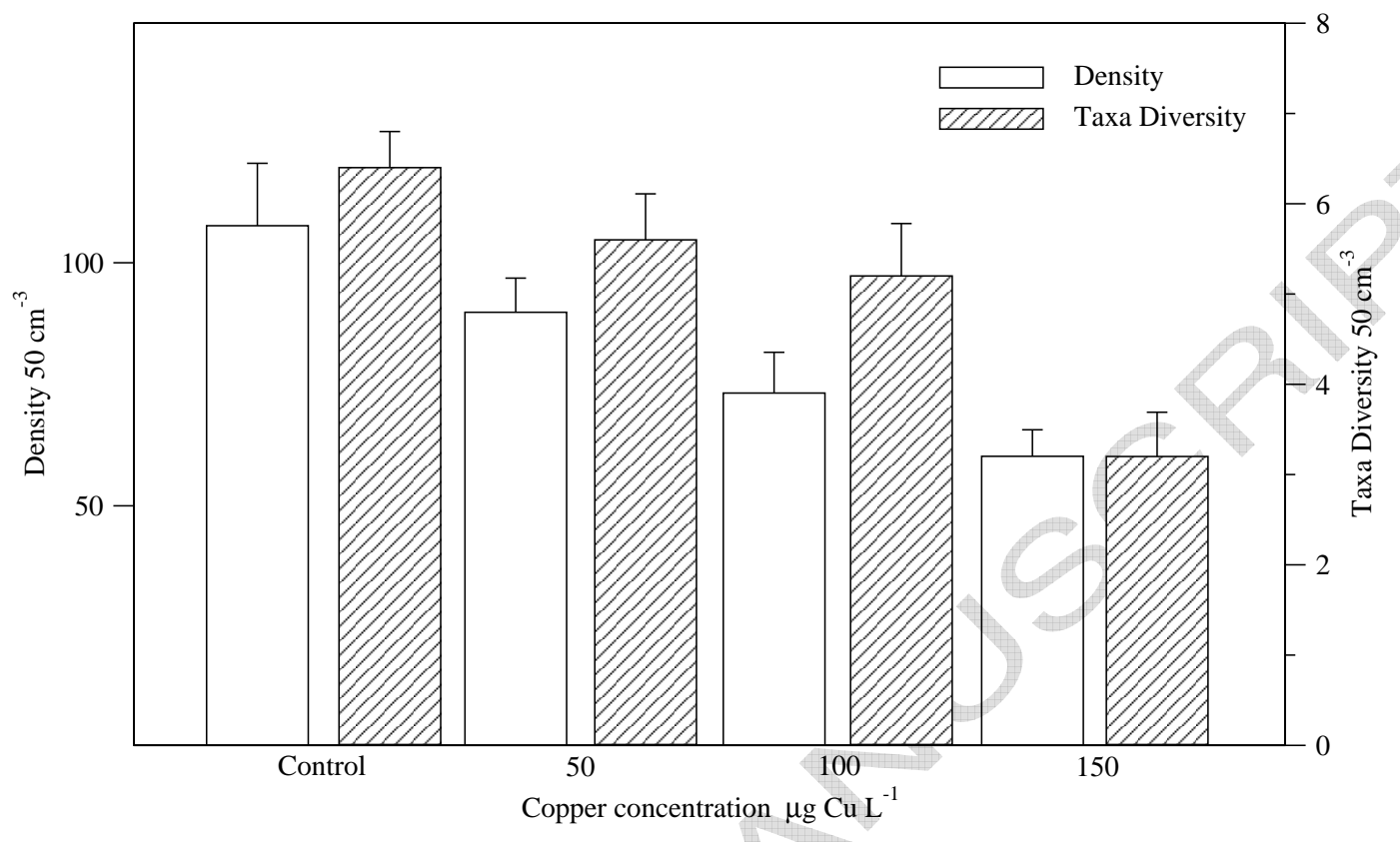

Fig. 3. Changes in meiofaunal assemblage density and taxa diversity in a series of copper spiked sediments (Error bars $=$ standard errors).

\subsection{Tailings substitute microcosms}

There was a significant increase in meiofaunal assemblage densities $(\mathrm{H}=$ 14.988, $\mathrm{p}=0.002)$ and a significant decrease in taxa diversities $(\mathrm{H}=10.962$, $\mathrm{p}=0.012$ ) with increasing amounts of tailings substitute (Fig. 4). The densities of foraminiferans increased with increasing tailings substitute $\mathrm{H}=14.737$, $\mathrm{p}=0.002)$. None of the other groups showed a significant change in density across the range of treatments. However, in the cases of harpacticoid copepods and ostracods the trend was a decrease in density with increasing amounts of tailings substitute 


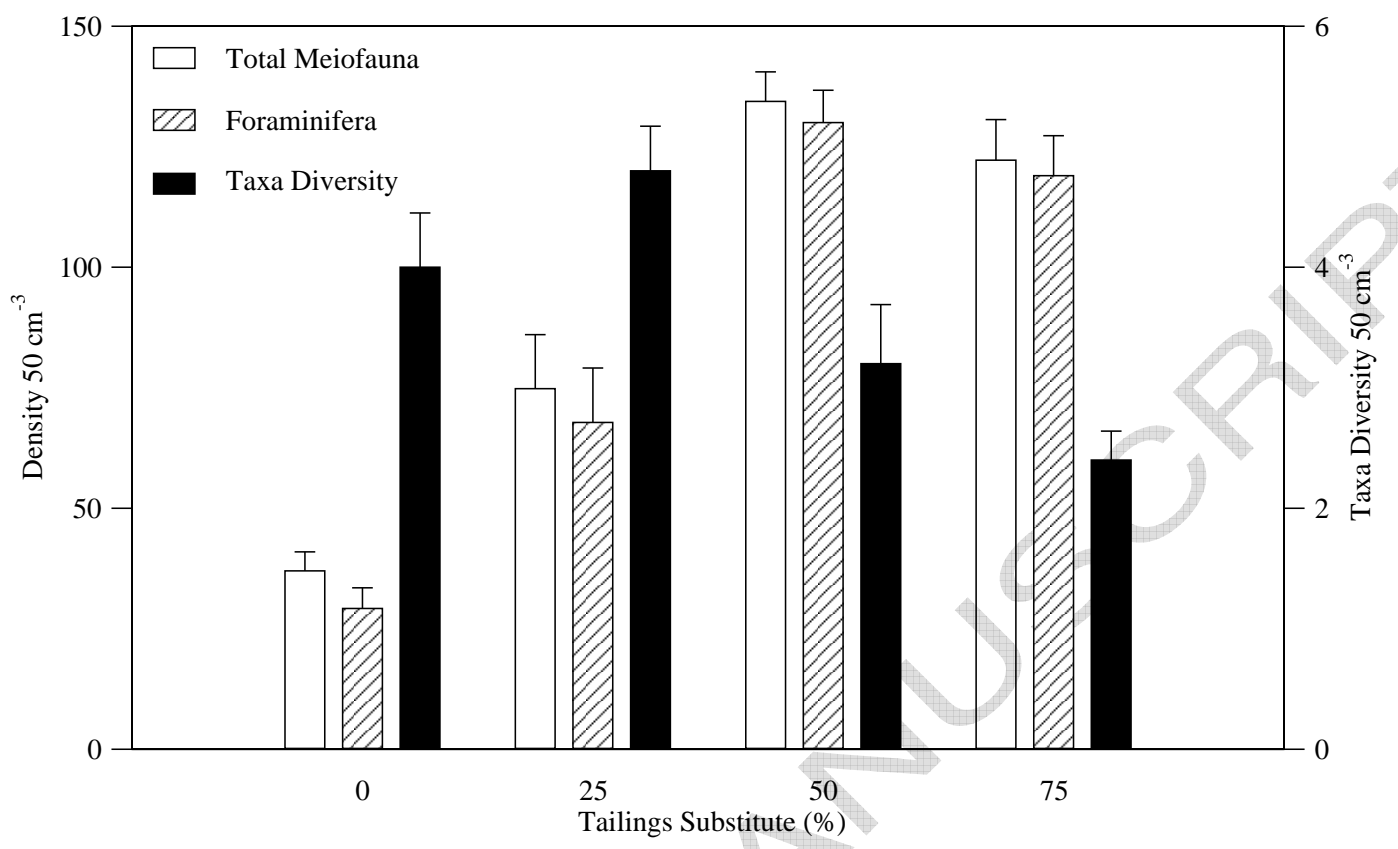

Fig. 4. Changes in meiofaunal assemblage taxa diversities, total and foraminiferal densities in response to increasing amounts of tailings substitute (Error bars $=$ standard errors).

\subsection{Sediment and seawaters bioassays}

The meiofaunal assemblage densities after exposure to the test sediments are presented in Figures 5a (coarse sites) and 5b (fine sites). For the coarse sites bioassays the meiofaunal assemblage densities were higher for Las Salinas and Puerto Pan de Azucar than they were for Palito 1000m Norte and Playa Palito (Fig. 5a). Furthermore, it was clear that the meiofaunal assemblage densities decreased with increasing labile copper concentrations. The fine site bioassays showed the same pattern as the coarse sites. Playa Grande and Playa Blanca had higher meiofaunal assemblage densities than Caleta La Lancha 
and Playa Chañaral. However, the relationship with labile porewater copper concentrations was less obvious. The meiofaunal assemblage densities after exposure to the test seawaters are presented in Figures 5c (coarse sites) and $5 \mathrm{~d}$ (fine sites). For the coarse sites bioassays the meiofaunal assemblage densities were similar for all sites, and there was no apparent relationship with the labile copper concentrations. For the fine sites, however, there were slightly lower meiofaunal assemblage densities for Caleta La Lancha and Playa Chañaral compared with Playa Grande and Playa Blanca, suggesting that there was a possible relationship between meiofaunal assemblage densities and the labile seawater copper concentrations.

There was a steady decline in meiofaunal assemblage taxa diversity with increasing labile porewater copper concentrations at the coarse sites (Fig. 6a). For the fine sites there was a clear difference between Playa Grande and Playa Blanca, and Caleta La Lancha and Playa Chañaral (Fig. 6b). The sites Caleta La Lancha and Playa Chañaral had higher labile porewater copper concentrations than Playa Grande and Playa Blanca. There was a slight decline in taxa diversity with increasing labile seawater copper concentrations for the coarse sites (Fig. 6c). For the fine sites there were slightly lower taxa diversities at Caleta La Lancha and Playa Chañaral when compared with Playa Grande and Playa Blanca (Fig. 6d).

There was significant variation in the meiofaunal assemblage densities between treatments for the coarse site sediment bioassays $(\mathrm{H}=14.992, \mathrm{p}=$ 0.002), but no significant variation in the meiofaunal assemblage taxa diversity. Of the four principal meiofaunal groups (foraminiferans, turbellarians, nematodes and harpacticoid copepods) there was a significant variation between treatments, except for turbellarians (foraminiferans: $\mathrm{H}=14.503, \mathrm{p}=$ 


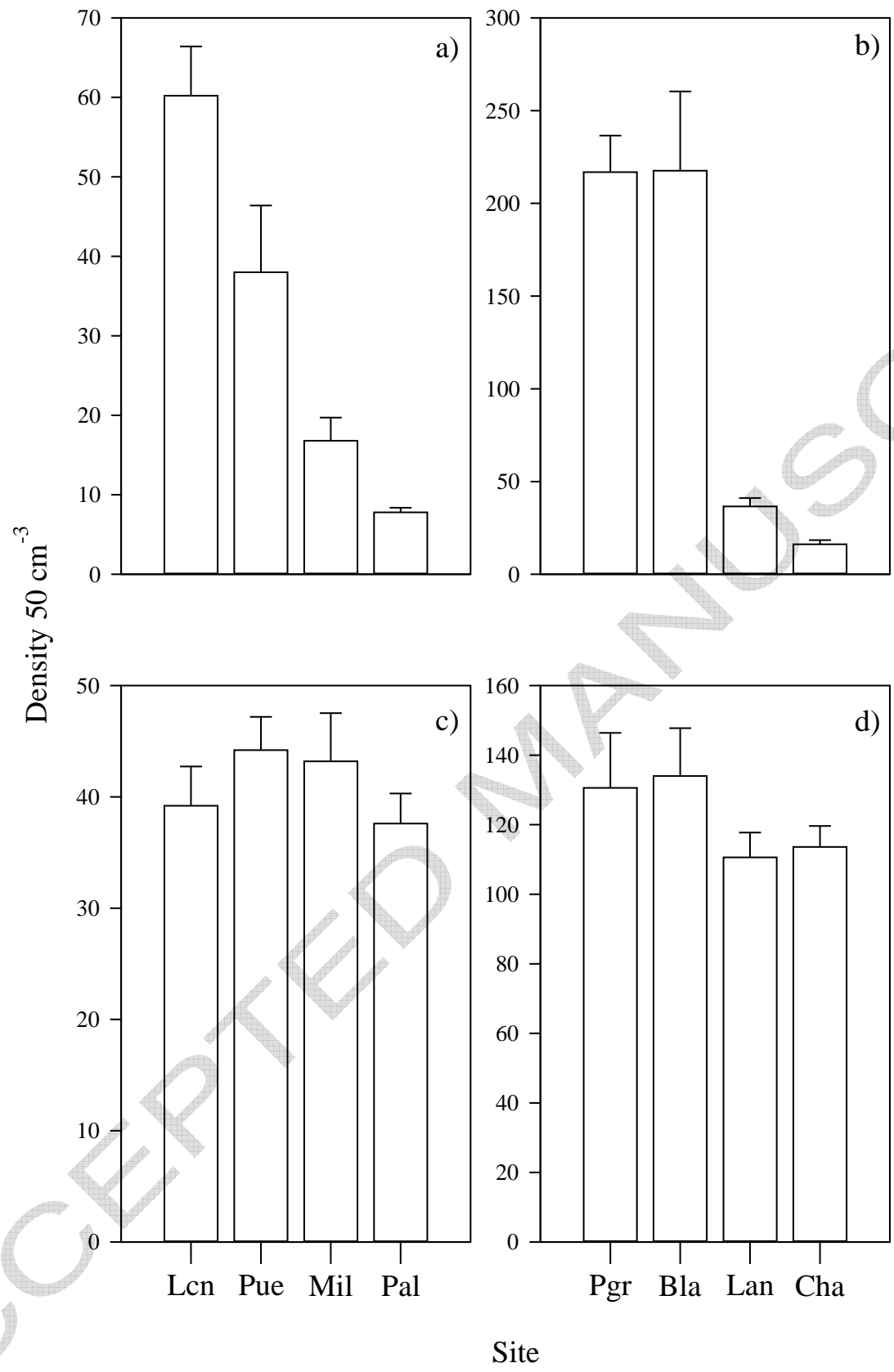

Fig. 5. Meiofaunal assemblage densities from microcosm bioassays of sediments and seawaters from the study sites. a) sediments - coarse sites, b) sediments - fine sites, c) seawaters - coarse sites, d) seawaters - fine sites (Error bars = standard errors). 

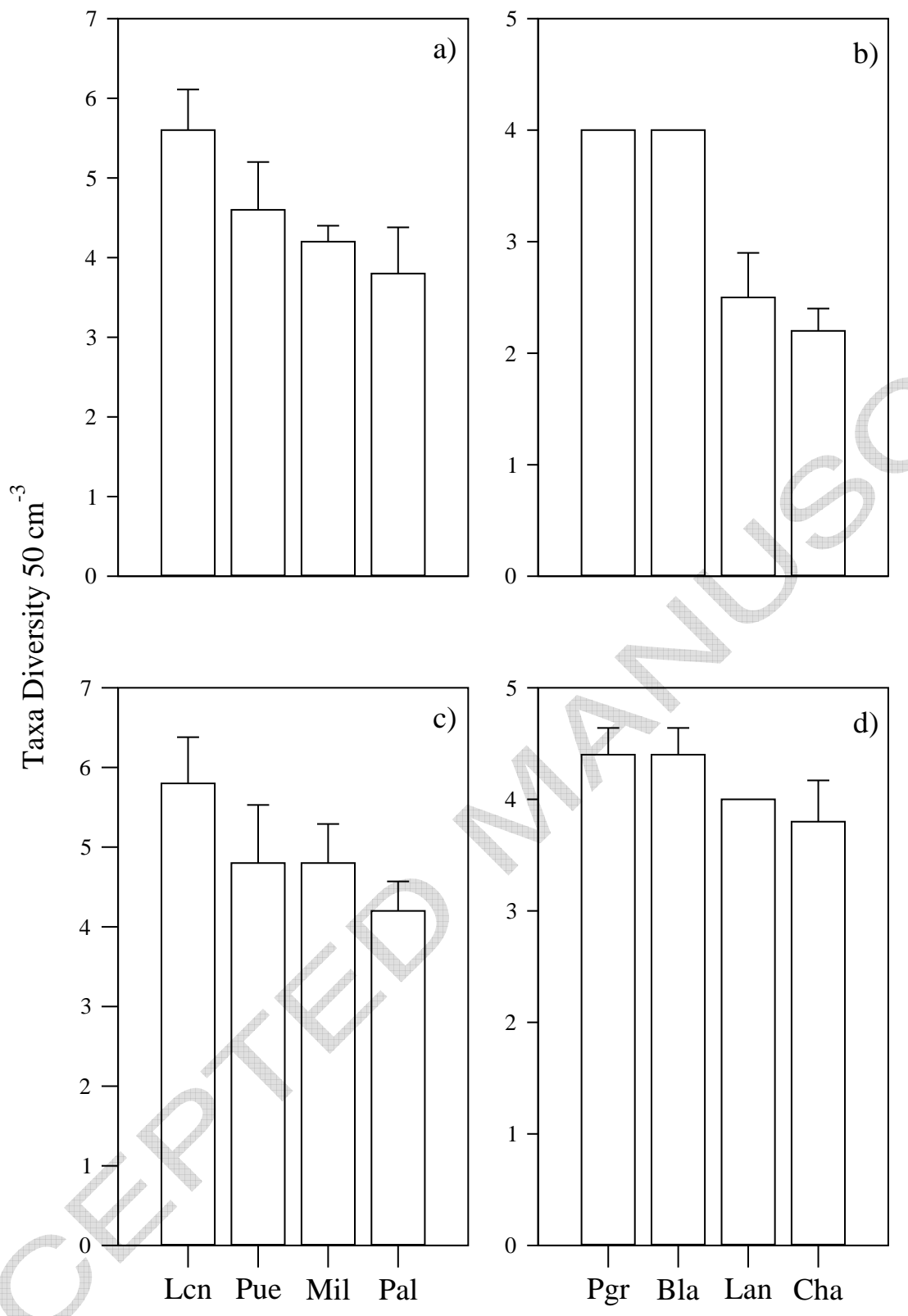

Site

Fig. 6. Meiofaunal assemblage taxa diversities from microcosm bioassays of sediments and seawaters from the study sites.a) sediments - coarse sites, b) sediments fine sites, c) seawaters - coarse sites, d) seawaters - fine sites (Error bars = standard errors). 
0.002, nematodes: $\mathrm{H}=8.904, \mathrm{p}=0.031$, harpacticoids: $\mathrm{H}=15.099, \mathrm{p}=$ 0.002). The meiofauna assemblage densities and taxa diversities varied significantly for the fine site sediment treatments (density: $\mathrm{H}=16.109, \mathrm{p}=0.001$, diversity: $\mathrm{H}=15.133, \mathrm{p}=0.002)$. The variation across the range of treatments was also significant for each of the four principal meiofaunal groups (foraminiferans: $\mathrm{H}=17.243, \mathrm{p}=0.001$, turbellarians: $\mathrm{H}=15.385, \mathrm{p}=0.002$, nematodes: $\mathrm{H}=16.896, \mathrm{p}=0.001$, harpacticoids: $\mathrm{H}=14.977, \mathrm{p}=0.002)$. The variation between treatments for the coarse site seawater bioassays was not significant. Additionally, neither the meiofaunal assemblage taxa diversity nor the four principal meiofaunal groups showed significant variation between treatments. For the fine site seawater bioassays there was also no significant variation between treatments for the meiofaunal assemblage densities. Of the four principal meiofaunal groups none showed significant variation between treatments with the exception of the harpacticoid copepods $(\mathrm{H}=8.767, \mathrm{p}=$ $0.033)$

ANOSIM analyses for the coarse site sediment bioassays indicated that there was significant variation between treatments $(\mathrm{R}=0.396, \mathrm{p}<0.0001)$. There were significant differences between all treatments in the pairwise comparisons, except for the comparison between Palito 1000m Norte and Playa Palito. There was also significant variation between treatments for the fine site sediment bioassays $(\mathrm{R}=0.705, \mathrm{p}<0.0001)$. Again there were significant differences between all treatments in the pairwise comparisons, except for the comparison between Playa Grande and Playa Blanca. The ANOSIM analysis of the coarse site seawater bioassay results indicated that there was no significant variation between treatments $(\mathrm{R}=0.029, \mathrm{p}=0.354)$. Neither were there any significant differences between treatments in the pairwise comparisons. For the fine site 
seawater bioassays again there was no significant variation between treatments $(\mathrm{R}=0.068, \mathrm{p}=0.161)$, and there were no significant differences between the treatments in pairwise comparisons. However, the comparison between Playa Blanca and Playa Chañaral is close to significance at $\mathrm{p}=0.079$.

The coarse site sediments bioassay MDS plot (Fig. 7a) had a high stress value (0.17) and therefore had to be treated with caution. It did not differentiate between the treatments; however, the dispersion of the points for each treatment indicated that Playa Palito was considerably more toxic than the other treatments. The fine site sediments bioassay MDS plot (Fig. 7b) had a very low stress value (0.01) indicating that it was a very good representation of the relationships between the treatments. The treatments were clearly separated into two groups, Playa Grande with Playa Blanca and Caleta La Lancha with Playa Chañaral. The dispersion of the points for each treatment indicated that Caleta La Lancha and Playa Chañaral were more toxic than Playa Grande and Playa Blanca. No plots for the seawater bioassays are presented as there were no significant differences between the treatments (ANOSIM analyses).

The foraminiferans in the coarse site sediment bioassays (Fig. 8a) showed a steady decline in density with increasing labile copper concentrations. Turbellarian numbers were very low and no pattern was discernable. The nematodes showed a broadly similar pattern to the foraminiferans. For the harpacticoid copepods there were higher densities at Las Salinas and Puerto Pan de Azucar than at Palito 1000m Norte and Playa Palito. The foraminiferan densities for the fine site sediment bioassays (Fig. 8b) showed a steady decline in response to increasing labile copper concentrations. Again the turbellarian densities were low but clearly higher for Playa Grande and Playa Blanca than for Caleta La Lancha and Playa Chañaral, suggesting a relationship with increasing labile 


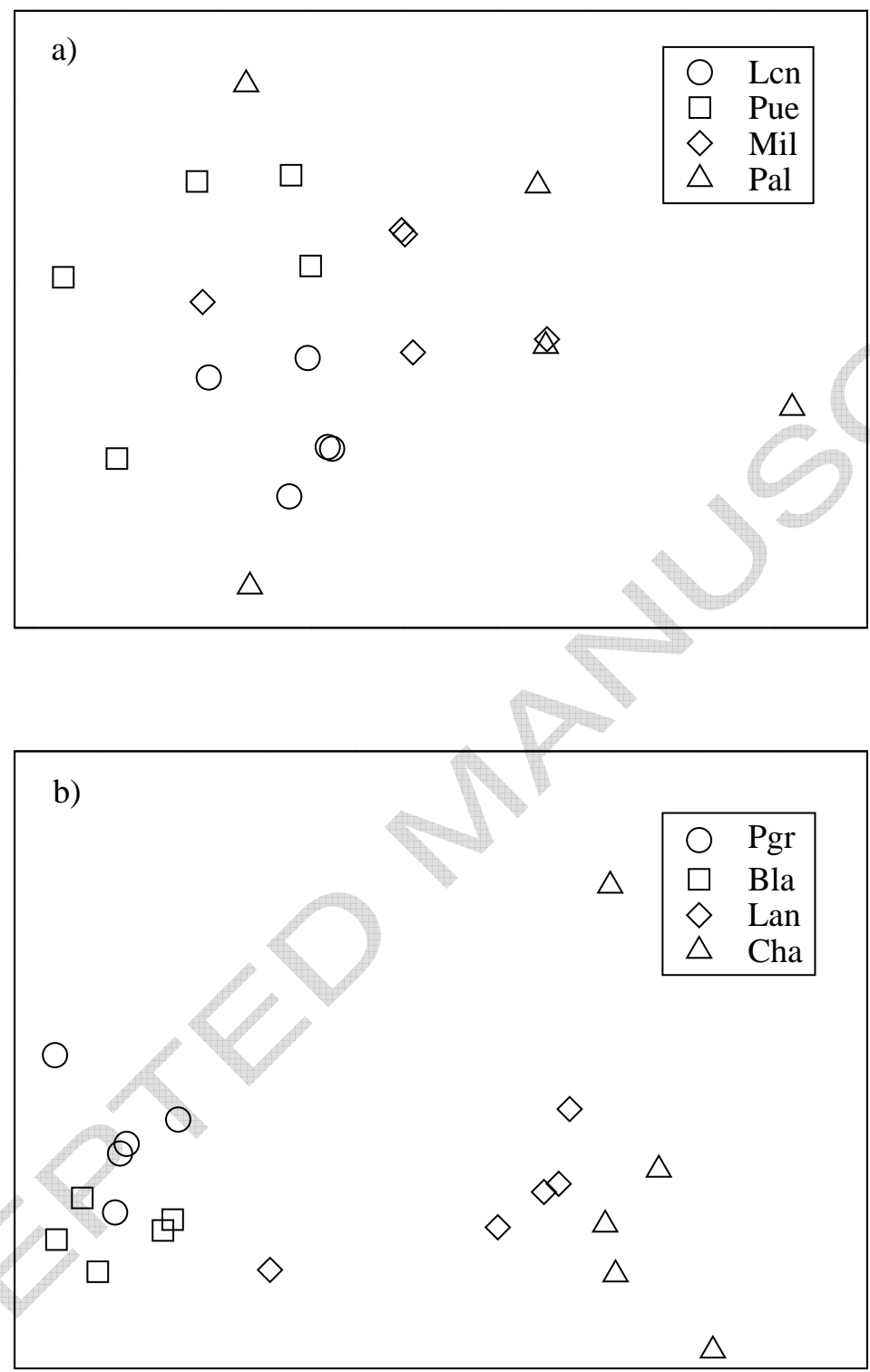

Fig. 7. Multi-dimensional scaling (MDS) plots of the sediment bioassays. a) coarse sites, b) fine sites. 
copper concentrations. The nematodes showed the same pattern as the turbellarians. The pattern for the harpacticoid copepods was broadly the same as for the turbellarians and nematodes, though densities were much higher for the harpacticoids.

For the coarse site seawater bioassays (Fig. 8c) the foraminiferan densities did not change and there was no apparent relationship between the foraminiferan densities and the labile copper concentration. This pattern held for the turbellarians and the nematodes, and to a lesser extent for the harpacticoid copepods, where the density for Las Salinas (the reference treatment) was higher than for the other three treatments. The picture for the fine site seawater bioassays (Fig. 8d) was similar to the coarse sites. There were no differences in foraminiferan densities between sites. The densities of turbellarians were low, although there was an apparent decline in turbellarian density with increasing labile copper concentrations. The nematodes showed the opposite relationship where densities increased with increasing labile copper concentrations. However these observed trends were not statistically significant. The harpacticoid copepod densities for Playa Grande and Playa Blanca were obviously, and significantly $(\mathrm{H}=8.767, \mathrm{p}=0.033)$ higher than for Caleta La Lancha and Playa Chañaral.

SIMPER analysis of the data indicated that for the coarse sites sediment bioassays the highest degree of similarity between the meiofaunal assemblages was between Las Salinas and Puerto Pan de Azucar the two least impacted sites (Table 2a). The harpacticoid copepods were the group most responsible for the differences between the assemblages in all comparisons, except that between Las Salinas and Puerto Pan de Azucar, the foraminiferans were the group most responsible for the differences between assemblages. The highest 


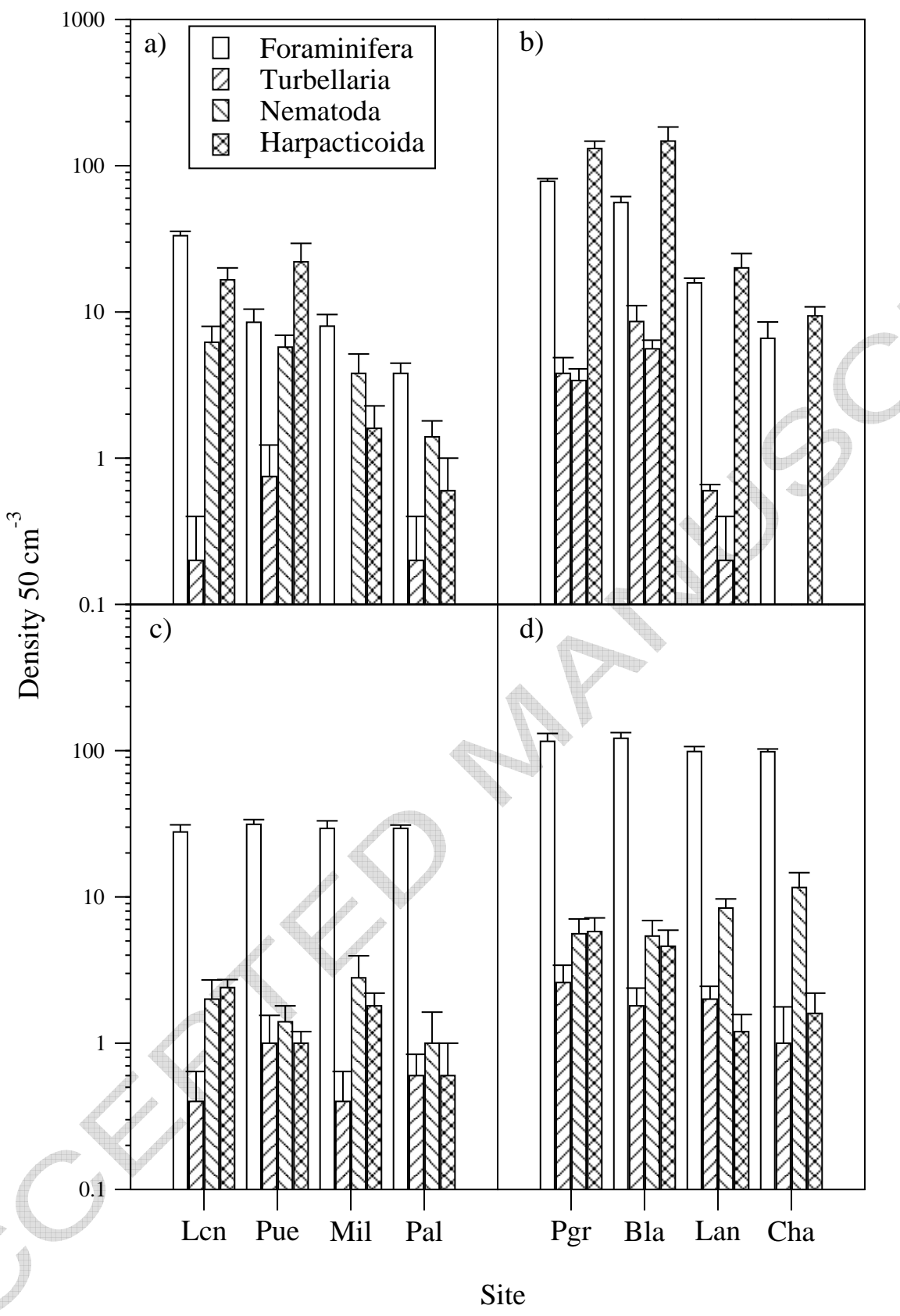

Fig. 8. Densities of the most abundant groups in the sediments and seawaters bioassays. a) sediments - coarse sites, b) sediments - fine sites, c) seawaters - coarse sites, d) seawaters - fine sites (Error bars = standard errors). 
Table 2

The average faunal similarity between bioassay treatments, determined using similarity percentage analysis (SIMPER) analysis

\begin{tabular}{|c|c|c|c|c|c|c|c|}
\hline & \multicolumn{3}{|c|}{ Coarse Sites } & \multicolumn{4}{|c|}{ Fine sites } \\
\hline & Sal & Pue & Mil & & $\mathrm{Pgr}$ & Bla & Lan \\
\hline Pue & 0.715 & & & Bla & 0.917 & & \\
\hline Mil & 0.713 & 0.679 & & Lan & 0.648 & 0.649 & \\
\hline Pal & 0.586 & 0.554 & 0.682 & Cha & 0.514 & 0.513 & 0.825 \\
\hline \multicolumn{8}{|c|}{ b)Seawater Bioassays } \\
\hline & \multicolumn{3}{|c|}{ Coarse Sites } & & \multicolumn{3}{|c|}{ Fine sites } \\
\hline & Sal & Pue & Mil & & Pgr & Bla & Lan \\
\hline Pue & 0.749 & & & Bla & 0.867 & & \\
\hline Mil & 0.692 & & & Lan & 0.852 & 0.881 & \\
\hline Pal & 0.720 & 0.757 & 0.676 & Cha & 0.798 & 0.813 & 0.840 \\
\hline
\end{tabular}

similarity between treatments for the fine sites sediment bioassays was between Playa Grande and Playa Blanca (Table 2a), although there was also a high degree of similarity between Caleta La Lancha and Playa Chañaral. For this set of bioassays the harpacticoid copepods were again the group most responsible for the differences between the assemblages. However, the turbellarians were more important for the comparisons between Playa Blanca and the tailings sites, Caleta La Lancha and Playa Chañaral.

Comparison of the meiofaunal assemblages for the seawater bioassays indi- 
cated that Puerto Pan de Azucar and Playa Palito for the coarse sites and Playa Blanca and Caleta La Lancha for the fine sites had the highest similarities (Table 2b). However, these distinctions between sites are finely judged as the assemblages for all the treatments were very similar. The nematodes contributed the most to the differences between assemblages for the coarse sites. For the fine sites there was little to choose between the turbellarians and the harpacticoid copepods with both contributing equally to the differences between the assemblages.

\section{Discussion}

The objective of this research was to establish a cause-effect relationship between elevated concentrations of porewater copper observed in the field (Lee et al., 2002) and the reduced densities and taxa diversities of the meiofaunal assemblages observed at the same sites (Lee \& Correa, 2005). The evidence presented here supports such a cause-effect relationship. Meiofaunal assemblages exposed to a series of copper spiked sediments showed a decrease in both density and taxa diversity with increasing copper concentrations. These observations were confirmed when meiofaunal assemblages were exposed to sediments from the impacted sites near Chañaral. Those sites known to have the highest concentrations of copper exhibited significantly lower meiofaunal assemblage densities and taxa diversities compared to the controls, which matched the situation in the field (Lee \& Correa, 2005) where the same sites had significantly lower meiofaunal assemblage densities and taxa diversities compared to the reference sites.

The physical impact of the tailings was difficult to distinguish from the over- 
all impact in the field. In the microcosms there was an increase in meiofaunal assemblage densities with increasing amounts of tailings substitute. However, this increase was entirely due to the surface utilising foraminiferans. If the foraminifierans are removed from the total meiofauna data, then there is a trend to decreasing meiofaunal density with increasing amounts of tailings substitute, probably due to a loss of the true interstitial species (see Lee \& Correa, 2004). This is supported by the decrease in taxa diversity with increasing amounts of tailings substitute. The increase in foraminifera as a result of the physical impact of the tailings was not observed in the field as foraminifera are sensitive to copper, and therefore, they decrease in abundance with increasing concentrations of copper (Lee \& Correa, 2005).

The major meiofaunal groups, with the exception of turbellarians, declined in abundance with increasing labile porewater copper, thus providing further evidence of the sensitivity of foraminiferans and harpacticoid copepods, and the insensitivity of turbellarians, to bioavailable copper already observed in the samples from the field (Lee \& Correa, 2005). The insensitivity to copper of the turbellarians is an important observation. The otoplanid turbellarians have a high tolerance for copper exhibiting near to zero mortality in toxicity tests with copper concentrations as high as $200 \mu \mathrm{g} \mathrm{L}^{-1}$ (M.R. Lee, unpublished data). In the field they appear to increase as a proportion of the meiofaunal assemblage when the concentration of porewater copper is higher. At Caleta La Lancha (100\% tailings) they constitute $95 \%$ plus of the meiofaunal assemblage (Lee \& Correa, 2005). Although nematodes did decline in abundance with increasing concentrations of copper, this result was not significant and it is consistent with the field studies done in the area (Lee \& Correa, 2005). Nematode communities exhibit an ability to develop tolerance to metals after 
prolonged exposure (Howell, 1984), which has led to the development of the Pollution Induced Community Tolerance (PICT) methodology using nematodes in the benthic marine environment (Millward \& Grant, 1995).

The sediment bioassays indicated that Playa Blanca is not an impacted site, clarifying inconclusive indications from our previous field data (Lee \& Correa, 2005). Therefore, the low meiofaunal assemblage density at Playa Blanca, compared with the reference sites and primarily due to a lack of harpacticoids, is probably the result of variables other than the tailings that were not measured in the study. However, another northern site, Puerto Pan de Azucar, was significantly different from the control supporting the evidence from the field data that it was indeed impacted. The sequence of impact within the northern sites does not appear to be related to distance from the discharge site at Caleta Palito, as Playa Blanca is closer than Puerto Pan de Azucar to Caleta Palito but does not appear to be impacted. This suggests that the movement of the tailings along the coast is more complex than just a longshore drift phenomenon. Playa Blanca lies within a deep embayment and it may be that the formation of a topographically controlled front across the mouth of the bay is sufficient to prevent the suspended tailings from entering the bay (Wolanski \& Hamner, 1988). Another cause could be the residual effect of the ore processing that took place at Puerto Pan de Azucar in the first part of the 20th century (J.C. Castilla. personal communication) and therefore the impact at this site may not be necessarily due to the tailings dumping at Caleta Palito.

The same effects on the meiofaunal assemblages were not observed in the seawater bioassays. This may, to a certain extent, be an artifact of the bioassay methodology where the test seawater was added directly to uncontaminated 
sediment and therefore it is inevitable that a new dynamic equilibrium would form to include the ligands present in the sediment (Chapman, Wang, Janssen, Persoone \& Allen, 1998). The significance of this is open debate, as the natural sediment used lacks many of the important ligands, such as acid volatile sulphides (AVS) and significant quantities of organic matter. The situation in the field, on the other hand, is different in that the sediment, though lacking the important ligands mentioned previously, has already been in contact with the seawater and therefore an equilibrium already exists. A future modification of the methodology would be to expose the uncontaminated sediment to the test seawater for 24 hour period in advance of the test to allow a chemical equilibrium to form (Ma, Kim, Cha \& Allen, 1999) and then add a second, fresh test seawater sample to the microcosm at the beginning of the test run. This would prevent a rapid change in the microcosm chemistry and therefore exposure conditions for the meiofaunal assemblages over the first few days of the test run. In the field we believe that the source of the copper in the seawater is primarily the tailing deposited at each site (Lee et al., 2002). In the seawater bioassays, only in the case of the harpacticoid copepods was there any evidence of impact. The abundance of harpacticoid copepods was significantly lower at Caleta La Lancha and Playa Chañaral, both $100 \%$ tailings sites, compared to the control and Playa Blanca, thus underlining the sensitivity of this group to bioavailable copper (van Damme et al., 1984; Lee, et al., 2001b; Lee \& Correa, 2005).

The only comparable studies in the literature where metal contaminated sediments have been taken from the field and placed in microcosms with test meiofaunal assemblages were conducted by Austin \& Somerfield (1997) and Millward et al. (2001). In the case of Austin \& Somerfield (1997) their as- 
semblages were dominated by nematodes, typical of fine sediment estuarine sites, and they only measured total metal concentrations. In spite of that, their results broadly agree with those reported here. They found that changes in the meiofaunal assemblage structure were related to increases in the sediment metal loadings, predominantly copper. Their bioassays also validated the findings of an earlier field study in the same area (Somerfield, Gee \& Warwick, 1994) underling the usefulness of the microcosm bioassay approach in assessing the effects of pollutants on sedimentary environments and confirming the cause-effect relationship. Their principal concerns with the methodology were the possible effects of the destruction of the sediment structure during the microcosm preparation and with the existence of a 'microcosm effect'. The concerns with the disruption of the sediment structure is more relevant in their estuarine sediments than in our high-energy sandy beach sediments where the vertical structure is less well defined. The main issue relevant to the metal chemistry in the estuarine sediments would be the presence of anoxic conditions and sulphides (Chapman et al., 1998). In the Chañaral sediments, however, anoxic conditions were not encountered on any of the beaches sampled (M.R. Lee, personal observation). The anoxic sediment layer, if it exists on these beaches, would lie well bellow the level of the sediment collected for our microcosm bioassays. The second issue of 'microcosm effect', where changes to the meiofaunal assemblage may be caused simply by confinement to the microcosm, was considered in the control experiments conducted before the bioassays. The observed 'microcosm effects' using this bioassay methodology were slight increases in foraminiferan and turbellarian densities. However, there were no significant differences in the meiofaunal assemblage densities or diversities between field and microcosm samples, nor were there any significant differences in the nematode and harpacticoid densities between field 
and microcosm samples (Lee, 2001a). The 'microcosm effect' only needs to be taken into account when relating the results of the bioassays to field data, as it does not affect the comparison of one microcosm bioassay with another. The experiments conducted by Millward et al. (2001) used saltmarsh communities, lower copper concentrations and shorter exposure times. However, the observed trends in meiofaunal abundance are broadly in agreement with those presented here. The density of harpacticoids decreased with increasing porewater copper concentrations and nematodes did not show a significant decrease in abundance with increasing porewater copper.

Bat \& Raffaelli (1998) summarised that to be useful, a sediment bioassay needs to have a number of desirable properties: (i) a high degree of sensitivity to the contaminants under consideration, (ii) a high survival rate in the control bioassay treatment, (iii) occupation of the microenvironment under consideration, preferably with an intimate and continuous contact with the sediments and porewaters, (iv) a low sensitivity to variability in the natural sediment parameters, for example sediment grain size, allowing a wide variety of sediment types to be tested, (v) a broad geographic range which can enhance the applicability of the bioassay, (vi) ease of collection, handling, and maintenance in the laboratory, (vii) ecological relevance and importance, (viii) easily cultured or year-round availability from the field and finally, (ix) the need to be rapid, simple, and inexpensive.

The bioassay presented here uses a complete meiofaunal assemblage collected from the field and exposed to the test sediments or seawater in a microcosm. By using the meiofaunal assemblage the protocol fulfils the first desirable property of a bioassay by providing a range of species with a range of sensitivities or end-points. In doing so it avoids the problems identified by McPherson \& 
Chapman (2000) of insensitive, and therefore inappropriate, species being used for bioassay analyses. The meiofauna live their entire lives in intimate association with the interstitial environment, fulfilling the third desirable property of the bioassay. The meiofauna, as individual species, are sensitive to natural variation in the sediment parameters (property iv). However, meiofauna as a group are common to all sedimentary environments in all parts of the world. Thus, the meiofaunal assemblage used can be ecologically relevant in terms of both the sedimentary environment and the geographic location, fulfilling properties v, vi, vii, and viii.

The meiofaunal assemblage microcosm also has a desirable property not outlined above, in that for some of the species in the assemblage it is possible that all the stages in the life-cycle will be exposed to the sediment over the six-week duration of the microcosms. The importance of this is that the lar$\mathrm{val} /$ juvenile stages of the life cycle are often the most sensitive to toxicants (Chandler \& Green, 2001). It is not always desirable, therefore, for the bioassay to be rapid. On the other hand, the microcosm bioassays used here do fulfil the other two components of property ix above, in that they are simple to set up and maintain and they are inexpensive.

In summary, the application of the microcosm bioassay approach has validated the findings of the field based studies (Lee \& Correa, 2005) and established the cause-effect relationship. Sites known to have high concentrations of bioavailable copper compared to the reference sites had lower densities of meiofauna, particularly of those groups identified previously as being sensitive to copper, e.g. harpacticoid copepods (Lee, et al., 2001b). In addition, the bioassays were able to provide further information on the impact status of some of the northern sites, particularly Playa Blanca, indicating that it is not impacted by 
the dumping of tailings at Caleta Palito. The bioassay methodology presented here fulfils the majority of the desirable properties outlined by Bat \& Raffaelli (1998) and has proved useful as a component of an SQT approach (Long \& Chapman, 1985) in assessing pollution impact in coastal sediments.

\section{Acknowledgements}

We thank Bernardo Broitman, Evie Weiters, Marco Ramierez for assistance in the field. Dr Hao Zhang for the metal analyses. This study was initially supported by the International Copper Association and later by FONDAP 1501-0001 to the Center of Advanced Studies in Ecology and Biodiversity.

\section{References}

Austin, M.C., McEvoy, A.J. \& Warwick, R.M. (1994) The specificity of meiobenthic community responses to different pollutants: results from microcosm experiments. Marine Pollution Bulletin, 28, 557-563.

Austin, M.C. \& Somerfield, P.J. (1997) A community level sediment bioassay applied to an estuarine heavy metal gradient. Marine Environmental Research, 43, 315-328.

Bat, L. \& Raffaelli, D. (1998) Sediment toxicity testing: a bioassay approach using the amphipod Corophium volutator and the polychaete Arenicola marina. Journal of Experimental Marine Biology and Ecology, 226, 217-239.

Carman, K.R., Fleeger, J.W. \& Pomarico, S.M. (2000) Does historical exposure to hydrocarbon contamination alter the response of benthic communities to diesel contamination? Marine Environmental Research, 49, 255-278. 
Castilla, J.C. (1983) Environmental impact in sandy beaches of copper mine tailings at Chañaral, Chile. Marine Pollution Bulletin, 14, 459-464.

Castilla, J.C. \& Nealler, E. (1978) Marine environmental impact due to maining activities of El Salvador copper mine, Chile. Marine Pollution Bulletin, $9,67-70$.

Chandler, G.T., Coull, B.C., Schizas, N.V. \& Donelan, T.L. (1997) A culture based assessment of the effects of chlorpyrifos on multiple meiobenthic copepods using microcosms of intact estuarine sediments. Environmental Toxicology and Chemistry, 16, 2339-2346.

Chandler, G.T. \& Green, A.S. (2001) Developmental stage-specific life-cycle bioassay for assessment of sediment-associated toxicant effects on benthic copepod production. Environmental Toxicology and Chemistry, 20, 171-178.

Chapman, P.M. \& Long, E.R. (1983) The use of bioassays as part of a comprehensive approach to marine pollution assessment. Marine Pollution Bulletin, 14,81-84.

Chapman, P.M., Wang, F., Janssen, C., Persoone, G. \& Allen, H.E. (1998) Ecotoxicology of metals in aquatic sediments: binding and release, bioavailability, risk assessment, and remediation. Canadian Journal of Fisheries and Aquatic Science, 55, 2221-2243.

Clarke, K.R. (1993) Non-parametric multivariate analyses of changes in community structure. Australian Journal of Ecology., 18, 117-143.

Clarke, K.R. \& Green, R.H. (1988) Statistical design and analysis for a 'biological effects' study. Marine Ecology Progress Series, 46, 213-226.

Coull, B.C. (1988) Ecology of the marine meiofauna. In: Higgins, R.P. \& Thiel, H. (Eds.) Introduction to the study of meiofauna. Smithsonian Institute Press. Washington D.C. pp.134-145.

Coull, B.C. \& Chandler, G.T. (1992) Pollution and Meiofauna: Field, labo- 
ratory, and mesocosm studies. Oceanography and Marine Biology Annual Review, 30, 191-271.

Davidson, W. \& Zhang, H. (1994) In situ speciation measurements of trace components in natural waters using thin film gels. Nature, 367, 546-548.

Field, J.G., Clarke, K.R. \& Warwick, R.M. (1982) A practical strategy for analysing multispecies distribution patterns. Marine Ecology Progress Series, 8, 37-52.

Findlay, S.E.G. (1981) Small scale spatial distribution of meiofauna on a mud and sand flat. Estuarine and Coastal Shelf Science, 12, 471-484.

Gross, O. (2000) Influence of temperature, oxygen and food availability on the migrational activity of bathyal benthic foraminifera: evidence by microcosm experiments. Hydrobiologia, 426, 123-137.

Howell, R. (1984) Acute toxicity of heavy metals to two species of marine nematodes Marine Environmental Research, 11, 153-161.

Jaramillo, E. (1994) Patterns of species richness in sandy beaches of South America. South African Journal of Zoology, 29, 227-234.

Jaramillo, E., McLachlan, A. \& Coetzee, P. (1993) Intertidal zonation patterns of macroinfauna over a range of exposed sandy beaches in south-central Chile. Marine Ecology Progress Series, 101, 105-118.

Johnson, B.T. (1986) Potential impact of selected agricultural chemical contaminants in a northern prairie wetland: a microcosm evaluation. Environmental Toxicology and Chemistry, 5, 473-486.

Kuhl, M., Lassen, C. \& Jorgensen, B.B. (1994) Light penetration and light intensity in sandy marine sediments measured with irradiance and scalar irradiance fibre optic micro-probes. Marine Ecology Progress Series, 105, $139-148$.

Lauth, J.R., Scott, G.J., Cherry, D.S. \& Buikema Jr., A.L. (1996) A modular 
estuarine microcosm. Environmental Toxicology and Chemistry, 15, 630-637.

Lawler, S.P. (1998) Ecology in a bottle. Using microcosms to test theory. In: Resetarits Jr., W.J. \& Bernardo, J. (Eds.) Experimental ecology: issues and perspectives. Oxford University Press, Oxford. pp. 236-253

Lee, M.R. (2001a) The effects of the disposal of copper mine tailings on littoral meiofaunal assemblages of the Chañaral area of northern Chile. PhD Thesis, University of Wales, Bangor. 147pp.

Lee, M.R., Correa, J.A. \& Castilla, J.C. (2001b) An assessment of the potential use of the nematode to copepod ratio in the monitoring of metals pollution. The Chañaral case. Marine Pollution Bulletin, 42, 696-701.

Lee, M.R., Correa, J.A. \& Zhang, H. (2002) Effective metal concentrations in porewater and seawater labile metal concentrations associated with copper mine tailings disposal into the coastal waters of the Atacama region of northern Chile. Marine Pollution Bulletin, 44, 956-961.

Lee, M.R. \& Correa, J.A. (2004) Copper mine tailings disposal: Consequences for the interstitial polychaete Saccocirrus sonomacus (Canalipalpata, Protodrilida). Journal of the Marine Biological Association, United Kingdom, 84, 603-606.

Lee, M.R. \& Correa, J.A. (2005) The effects of copper mine tailings disposal on littoral meiofaunal assemblages in the Atacama region of northern Chile. Marine Environmental Research, 59, 1-18.

Long, E.R. \& Chapman, P.M. (1985) A sediment quality triad: Measures of sediment contamination, toxicity and infaunal community composition in Puget Sound. Marine Pollution Bulletin, 16, 405-415.

Ma, H., Kim, S.D., Cha, D.K. \& Allen, H.E. (1999) Effects of kinetics of complexation by humic acid on the toxicity of copper to Ceriodaphnia dubia. Environmental Toxicology and Chemistry, 18, 828-837. 
McPherson, C.A. \& Chapman, P.M. (2000) Copper effects on potential sediment test organisms: the importance of appropriate sensitivity. Marine Pollution Bulletin, 40, 656-665.

Meador, J.P., Taub, F.B. \& Sibley, T.H. (1992) Copper dynamics and the mechanism of ecosystem level recovery in a standard aquatic microcosm. Ecological Applications, 2, 139-155.

Millward, R.N. \& Grant, A. (1995) Assessing the impact of copper on nematode communities from a chronically metal-enriched estuary using pollutioninduced community tolerance. Marine Pollution Bulletin, 30, 701-706.

Millward, R.N., Carman, K.R., Fleeger, J.W., Gambrell, R.P., Powell, R.T. \& Rouse, M-A.M. (2001) Linking ecological impact to metal concentrations and speciation: A microcosm experiment using a salt marsh meiofaunal community. Environmental Toxicology and Chemistry, 20, 2029-2037.

O’Neill, E.J., Cripe, C.R., Mueller, L.H., Connolly, J.P. \& Prichard, P.H. (1989) Fate of fenthion in salt-marsh environments: II. Transport and biodegredation in microcosms. Environmental Toxicology and Chemistry, 8, 759768.

Pfannkuche, O. \& Thiel, H. (1988) Sample processing. In: Higgins, R.P. \& Thiel, H. (Eds.) Introduction to the study of meiofauna. Smithsonian Institute Press. Washington D.C. pp.134-145.

Schratzberger, M., Wall, C.M., Reynolds, W.J., Reed, J. \& Waldock, M.J. (2002) Effects of paint-derived tributyltin on structure of estuarine nematode assemblages in experimental microcosms. Journal of Experimental Marine Biology and Ecology, 272, 217-235.

Somerfield, P.J., Gee, J.M. \& Warwick, R.M. (1994) Soft sediment meiofaunal community structure in relation to a long-term heavy metal gradient in the Fal estuary system. Marine Ecology Progress Series, 105, 79-88. 
Suderman, K \& Thistle, D (2003) Spills of fuel oil \#6 and Orimulsion can have indistinguishable effects on the benthic meiofauna. Marine Pollution Bulletin, 46, 49-55.

Van Beelen, P., Fleuren-Kemila, A.K., Huys, M.P.A., van Montfort, A.C.P. \& van Vlaardingen, P.L.A. (1991) The toxic effects of pollutants on the mineralization of acetate in subsoil microcosms. Environmental Toxicology and Chemistry, 10, 775-790.

van Damme, D., Heip, C. \& Willems, K.A. (1984) Influence of pollution on the harpacticoid copepods of two North Sea estuaries. Hydrobiologia, 112, $143-160$.

Warwick, R.M. (1988) The level of taxonomic discrimination required to detect pollution effects on marine benthic communities. Marine Pollution Bulletin, $19,259-268$.

Wolanski, E. \& Hamner, W.M. (1988) Topographically controlled fronts in the ocean and their biological influence. Science, 241, 177-181.

Zhang, H. \& Davidson, W. (1995) Performance characteristics of the technique of diffusion gradients in thin-films (DGT) for the measurement of trace metals in aqueous solution. Analytical Chemistry, 67, 3391-3400.

Zhang, H., Zhao, F-J., Sun, B., Davidson, W. \& McGrath, S.P. (2001) A new method to measure effective soil solution concentration predicts copper availability to plants. Environmental Science and Technology, 35, 2602-2607. 